\title{
A conversation with Katalin Karikó
}

It months of 2021, mRNA-based vaccines against SARS-CoV-2 have saved 280,000 lives in the US alone and prevented well over a million hospitalizations. It is the scientific body of work of biochemist Katalin Karikó (Figure 1), Senior Vice President at BioNTech SE, that made these vaccines possible. Karikó's work on nucleoside modifications to suppress immunogenicity of RNA provided the key to successful vaccines and an exit from the global COVID pandemic. To see the full interview with Dr. Karikó, visit https://www.jci.org/videos/cgms.

JCI: Can you start by telling us about your family and what you were like as a child?

Karikó: I grew up in Hungary in a small town of 10,000 people. My father was a butcher, and my mother was a bookkeeper, and we lived in a very simple home. I didn't realize how many things we didn't have because other neighbors didn't have them either: running water, television, or refrigerators. We went to the middle of the street for water, and it was also the chat room where you learned everything going on.

I was not super brilliant. I loved plants, and when I went to the University of Szeged, I thought that I would study plants and then everybody said, "Oh, that's so boring." But I love plants.

As an undergraduate, I worked at the Biological Research Center, Szeged, Hungary, and studied lipids, again, something everybody thought was boring. One day, Jenö Tomasz walked in - he had an RNA lab and knew that I was finishing up, so I went to his lab for my PhD. It was then, in 1977, when Ian Kerr discovered 2'-5' oligoribonucleotide and it was thought that the interferon-induced antiviral mechanism was mediated by this small molecule. Tomasz thought that if we could synthesize and deliver it to the cells, it would be a great antiviral compound. We synthesized it and set up the assay to check its antiviral effects, but the method was not applicable for medical use. We ran out of support, and

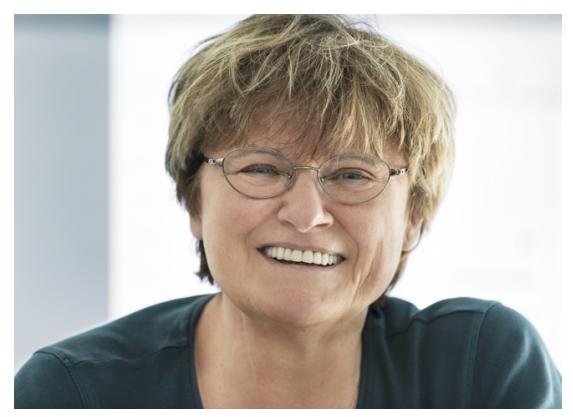

Figure 1. Katalin Karikó after sharing the 2021 Lasker DeBakey Clinical Medical Research Award. Image credit, BioNTech, Stefan Albrecht.

I had to find another position. I tried applying for jobs in London, Madrid, and Montpellier. But I couldn't bring any money, and in 1985 finally ended up in Philadelphia at Temple University, where Robert Suhadolnik was also interested in this small trimer RNA, 2-5A molecule.

They had run a clinical trial where they used a mismatched double-stranded RNA to treat HIV patients - at that time, HIV infection meant a death sentence. The idea was that double-stranded RNA could induce interferon. It turned out that it did not help HIV patients, but we tried. That was the first clinical trial with RNA in which I participated, and we published it in Lancet.

JCI: Why transition off such an exciting set of trials?

Karikó: I lost my job at Temple and had to go somewhere, and I ended up at the Uniformed Services University of the Health Sciences. I started there in ' 88 and one day, a former fellow from the lab came to visit and offered us lipofectin to deliver nucleic acids inside the cell. Given my prior experience with lipids and liposomes, I had an aha moment and took the lipofectin and tested it there and when I came back for a job at University of Pennsylvania, I tried using lipofectin to deliver mRNA. The field had advanced: mRNA could be made in vitro thanks to Paul Krieg and Douglas
Melton. Paul Krieg sent me the plasmid just put in an envelope, no transfer agreement or anything; I am so grateful to them.

I had come to Penn to work with Elliot Barnathan, a cardiologist with NIH funding. We started to make mRNA with the goal of improving blood vessel transplants. We wanted to understand the role of the urokinase receptor and tissue plasminogen activator in blood clots. We delivered the mRNA encoding the receptor, and once we happily watched an old dot matrix printer beeping as a readout for an experiment showing we could create functional receptors, we knew that the mRNA would be good for something, for example, using it ex vivo to deliver telomerase-encoding RNA into bone marrow cells. We thought that the life span of the cells could be increased.

JCI: You're riding this wave of success when Barnathan decided to leave for Centocor.

Karikó: I met a neurosurgery resident, David Langer in Barnathan's lab, and he convinced the chairman that Neurosurgery needed a molecular biologist. They gave me my first independent lab, and I stayed there 17 years. With David, we focused on stroke and subarachnoid hemorrhage. David thought that he could reach that critical area, and the dream was to deliver nitric oxide synthase mRNA. The protein would be locally made and release nitric oxide, which has a couple of millisecond half-life, but would cause the blood vessels to dilate. We expended a lot of effort. Nothing was published because we couldn't reliably demonstrate that blood vessel dilatation occurs. In the meantime, RNA research advanced, and the constant improvement of the technology kept us moving forward.

JCI: How did you come to know Drew Weissman and move into the next chapter of your story?

Karikó: I kept going back to my old friends in the Department of Medicine. I could see this new guy who was also using the xerox machine to copy papers. I introduced myself because I thought that I am home and he's the new one. He told me that he just came from Tony Fauci's lab 
and that he wanted to develop an HIV vaccine, which could be maybe therapeutic or prophylactic, and he's working with dendritic cells. I admit now that I did not know anything about that cell type. I thought, with dendrites, maybe it was some kind of neuronal cell, but it turned out that it's the most important antigen-presenting immune cell.

I said, "Oh, I work with mRNA and I can make mRNA for you." Not surprising because I offered that to many scientists on campus and there's likely freezers across Penn with mRNA from me. But Drew tested my HIV gag mRNA on human dendritic cells and he was very happy; he came back and said that so much protein was produced from the mRNA and it was also a good adjuvant because activation markers were expressed by the cells and inflammatory cytokines, including TNF- $\alpha$, were secreted. He was happy, but I was disappointed because I knew it wouldn't eventually work therapeutically if it triggered inflammation.

I had already made mRNA coding for enzymes like catalase and glutathione peroxidase to eliminate oxidative molecules (considered to be detrimental for the stroke patients), so I didn't want to deliver mRNA that would cause more problems for them.

I thought about why single-stranded RNA would trigger immune activation. I had spent ten years trying to make a therapeutic protein-encoding mRNA, and all of it was useless. In 2001, we knew that TLR3 was activated by double-stranded RNA and TLR9 was triggered by DNA. We made all of the TLR-overexpressing cells and found that TLR7 and TLR8 were being activated by the mRNA I made, and simultaneously, this was confirmed in the literature. The question was if we could make mRNA that is nonimmunogenic. Screening different RNAs isolated from human cells, we found that tRNA was not immunogenic, and that gave us the idea that maybe nucleoside modification is important to suppress immunogenicity of the RNA.

JCI: Was tRNA one of your controls or was it an inspired choice?

Karikó: I was testing the immunogenicity of different RNAs and also had a repertoire of homopolymers and many other different RNAs. In 2004, we had already published that polyuridine activates and polyadenylate suppresses immunogenicity of the RNA. When I added a cap and longer poly A tail to the mRNA, it induced a lesser immune response. In some of those experiments, I had also added tRNA as another control because I had it in my collection. I looked back at my data, saw tRNA was not inducing anything when it came to mind that, okay, why am I focusing on the poly A tail and cap that have some negligible but significant effect, while the tRNA was not inducing any cytokines? At the beginning, I thought it was because tRNA is short, but then we found that tRNA is not immunogenic at all.

I called up my friend, a Hungarian fellow scientist, Tamás Kiss in Toulouse, who had discovered how the ribosomal RNA gets to 2'-O methylation and pseudouridylation. I asked him to send me the enzymes, but he said it wasn't so simple and that I needed more than just the enzymes. Then I thought maybe T7 RNA polymerase would work if we had triphosphates of modified nucleosides. I ordered only those that are naturally present in our body because in 1993, I was reading about the fialuridine [nucleoside analogue tested as a therapy for hepatitis B] fiasco when five volunteers died from the 15 who participated in the NIH clinical trial, even though in monkeys, fialuridine was not toxic.

They couldn't understand why for quite a long time. In 2006, they published that humans have a nucleoside transporter with a mitochondrial localization signal in the middle of the coding sequence. If you give human cells nucleoside analogs that are naturally not present in the human body, they pump into the mitochondria and destroy them. Those people in the trial died of acidosis because they lost their mitochondria.

So I insisted on making mRNA using only nucleotides that were naturally present in the human body because then the patient's body would know how to discard them after degradation. We purchased ten different modified nucleoside triphosphates, five of them incorporated. Three of them were uridine containing, and all of those were nonimmunogenic. One mRNA contained pseudouridine; not only was it nonimmunogenic, but we got ten times more protein. We repeated the experiments and still got so much protein; as it turned out, pseudouridine-containing mRNA was remarkably more stable.

JCI: You narrow the modification to pseudouridine and see this massive increase in protein and no immunogenicity. Did you have champagne?

Karikó: No, because then immediately we were thinking that we have to see that it works in vivo. We used double-stranded RNA-specific antibodies and realized that when we make mRNA in vitro, our isolates had double-stranded RNA contaminants. So our mRNA was not good enough. We spent another two years figuring out how to purify it because we had the long RNA strand and then these phage polymerases just randomly made complementary sequences.

We kept trying to denature the doublestranded RNA with urea - it was easiest and our favorite one, but by the end, urea crystals were everywhere in the lab. We tried to take apart the two RNA strands and then isolate it. Drew Weissman would come to my lab after taking care of HIV patients and would run another column because, during the night, he had read something and wanted to try new strategies.

Eventually, we could purify and show a significant improvement in translation, especially in animals. We established a company (RNARx) in 2006. Unfortunately, we couldn't obtain our own patent. We did mRNA coding for murine erythropoietin, and we delivered a very small amount (0.1 $\mu \mathrm{g}$ mRNA) into an animal, and that was sufficient to increase their hematocrit. When we used a pseudouridine-containing construct, no interferon was detectable, and even low doses were sufficient to increase hematocrit. With weekly injections, we could maintain high hematocrit, so we knew that the mRNA was translating to a functional protein without inducing any immune effect.

JCI: How did you transition to industry?

Karikó: My daughter, who has twice been an Olympic champion, had a rowing race in Lucerne in the summer of 2013. We stopped by Mainz on our way back home to Hungary. I was invited to give a lecture, and so I met Uğur Șahin, CEO of BioNTech, for the first time and told him that if BioNTech would use the nucleosidemodified mRNA, I would come and work there. He acknowledged that at that time he didn't think that the nucleoside mod- 
ification was important, but he wanted me to come and work with him. And so he said, "Okay."

I started to work on protein replacement for cancer therapy, not vaccines. The mRNA coding for four different cytokines was developed for treatment of melanoma or head and neck cancer. Even remotely located metastatic cancer could be eliminated in animal models, and now a human trial is ongoing, and we will see the results soon.

JCI: It must have been rather thrilling to watch as the SARS-CoV-2 vaccines came out.

Karikó: I recently received an email from the Meadowbrook Healthcare elderly care center. They described that one week after the residents were vaccinated with just the first shot, there were infections: 70 people in the facility were positive, but nobody died. They were so happy, so this September 2nd, they recognized me and held "Dr. Katalin Karikó appreciation day" with a T-shirt with my picture, and nothing can ever be as gratifying that seeing those people sitting in the sunshine and smiling. They had also sent me pictures on Mother's Day, when the first time the residents could see their loved ones. When you see those people, it touches you. No matter what prize you give me, nothing can generate that kind of feeling.

JCI: If you could not have been a scientist, what other career do you think could have captivated you over your life?

Karikó: My father wanted me to be a butcher, and I worked in the butcher shop, and we did sausages. But I have here a document from a high school book that was only for the teachers, so I had never seen it - I was 16 years old, and it was written that I would be a scientist, so I don't think anything else could have been right for me.

Ushma S. Neill 